\title{
On sense and reference: Examining the functional neuroanatomy of referential processing
}

\author{
Mante S. Nieuwland, ${ }^{\mathrm{a}, \mathrm{b}, \mathrm{c}, *}$ Karl Magnus Petersson, ${ }^{\mathrm{d}, \mathrm{e}, \mathrm{f}, \mathrm{g}}$ and Jos J.A. Van Berkum ${ }^{\mathrm{a}, \mathrm{d}, \mathrm{e}}$ \\ ${ }^{a}$ Department of Psychology, University of Amsterdam, Amsterdam, The Netherlands \\ ${ }^{\mathrm{b}}$ Department of Psychology, Tufts University, 490 Boston Avenue, Medford, MA 02155, USA \\ ${ }^{\mathrm{c}}$ MGH/MIT/HMS Athinoula A. Martinos Center for Biomedical Imaging, Charlestown, MA, USA \\ ${ }^{\mathrm{d}}$ Max Planck Institute for Psycholinguistics, Nijmegen, The Netherlands \\ ${ }^{\mathrm{e}}$ F.C. Donders Centre for Cognitive Neuroimaging, Radboud University Nijmegen, Nijmegen, The Netherlands \\ ${ }^{\mathrm{f}}$ Cognitive Neurophysiology Research Group, Department of Clinical Neuroscience, Karolinska Institutet, Stockholm, Sweden \\ ${ }^{\mathrm{g}}$ Centre for Intelligent Systems, Faculty of Sciences and Technology, Universidade do Algarve, Faro, Portugal
}

Received 9 January 2007; revised 19 May 2007; accepted 28 May 2007

Available online 7 June 2007

In an event-related fMRI study, we examined the cortical networks involved in establishing reference during language comprehension. We compared BOLD responses to sentences containing referentially ambiguous pronouns (e.g., "Ronald told Frank that he..."), referentially failing pronouns (e.g., "Rose told Emily that he...") or coherent pronouns. Referential ambiguity selectively recruited medial prefrontal regions, suggesting that readers engaged in problemsolving to select a unique referent from the discourse model. Referential failure elicited activation increases in brain regions associated with morpho-syntactic processing, and, for those readers who took failing pronouns to refer to unmentioned entities, additional regions associated with elaborative inferencing were observed. The networks activated by these two referential problems did not overlap with the network activated by a standard semantic anomaly. Instead, we observed a double dissociation, in that the systems activated by semantic anomaly are deactivated by referential ambiguity, and vice versa. This inverse coupling may reflect the dynamic recruitment of semantic and episodic processing to resolve semantically or referentially problematic situations. More generally, our findings suggest that neurocognitive accounts of language comprehension need to address not just how we parse a sentence and combine individual word meanings, but also how we determine who's who and what's what during language comprehension.

(C) 2007 Elsevier Inc. All rights reserved.

Keywords: Anaphoric processing; Functional neuroimaging; Pronoun resolution; Referential ambiguity; Referential failure; Semantic anomaly

\footnotetext{
* Corresponding author. Department of Psychology, Tufts University, 490 Boston Avenue, Medford, MA 02155, USA. Fax: +1 6176273181. E-mail address: mante@nmr.mgh.harvard.edu (M.S. Nieuwland). Available online on ScienceDirect (www.sciencedirect.com).
}

\section{Introduction}

At least since Frege (1892), a distinction has been made between a word's general, dictionary-like meaning (sense) and the particular entity it denotes (reference). This distinction becomes clear when one compares, for example, the meaning carried by the word 'doctor' in (1) Hannibal Lecter is a doctor, and in (2) Hannibal Lecter is eating a doctor. The lexical item 'doctor' has an identical sense in 1 and 2 (i.e., someone who has completed medical school), but it provides information about Hannibal Lecter in 1, while it refers to another, rather unfortunate doctor in 2 . Thus, to appreciate the meaning of a word in a given context, one must establish both the general, lexical meaning and the specific, referential meaning it conveys.

In psycholinguistics, sense and reference are often associated with semantic and referential analysis, respectively. Through semantic analysis, we retrieve the meaning of individual words from long-term memory and combine them into larger units of conceptual structure. Through referential analysis, we determine who's who and what's what by establishing the relationships between words in the discourse and entities in our mental representation of the world (e.g., persons, events, concepts, places), real or fictional. Alongside the phonological and syntactic aspects of language comprehension, semantic and referential analysis has been subjected to experimental investigation throughout the past decades (e.g., see Garnham, 2001; Carreiras and Clifton, 2004). Convergent evidence from behavioral measures and event-related potentials (ERPs) has suggested that listeners and readers immediately relate the semantic and referential meaning of incoming words to the global context (e.g., Kutas and Hillyard, 1980; Marslen-Wilson and Tyler, 1980; Nieuwland and Van Berkum, 2006b; Tanenhaus and Trueswell, 1995; Van Berkum et al., 1999). 
Importantly, results from ERP experiments show that the brain responds in different ways to problems with reference than to problems with either syntax or semantics. While semantic and syntactic processing are predominantly associated with the N400 and P600/LAN respectively (e.g., Friederici, 2002; Hagoort et al., 1999), referentially ambiguous nouns (e.g., "the girl" in a two-girl context) elicit a frontally dominant and sustained negative shift (Van Berkum et al., 1999; Van Berkum et al., 2003). This referentially induced ERP effect stems from having two suitable referential candidates for a single anaphor (Nieuwland et al., 2007; see Van Berkum et al., 2007, for review), and enables us to selectively track referential processing at the level that is most relevant for comprehension, the mental representation of the situation as described in the discourse (the situation model, Zwaan and Radvansky, 1998).

To examine the causal antecedents of this referentially induced frontal negativity, we have recently investigated how people establish reference for pronouns like "he" or "she". Pronouns have a rather shallow sense of their own and constitute our linguistic 'pointers' for maintaining reference to topics that are in the focus of our conversation (e.g., Gordon et al., 1993; Sanford and Garrod, 1989). Because pronouns are among the most frequently used words in many languages, pronoun resolution is often regarded as the textbook example of referential processing. Consistent with our findings for nouns, referentially ambiguous pronouns (e.g., "Ronald told Frank that he...") also elicit a frontal negative shift compared to referentially coherent pronouns (Nieuwland and Van Berkum, 2006a; Van Berkum et al., 2004). Furthermore, referentially failing pronouns (when no suitable referent is directly available, e.g., "Rose told Emily that he...") elicit a P600 effect (Nieuwland and Van Berkum, 2006a; Van Berkum et al., 2004), suggesting that readers initially try to find an appropriate antecedent within the given set of discourse entities (e.g., Garnham, 2001) and therefore initially ascribe the referential failure to a problem with the syntactic gender of the pronoun (e.g., Osterhout and Mobley, 1995; see Van Berkum et al., 2007, for discussion).

Taken together, the ERP findings suggest that the brain responds in qualitatively different ways to distinct problems with referential analysis (failure/ambiguity), and that both responses, in turn, differ from the brain's response to semantically unexpected words (semantic anomaly). However, these findings do not tell the whole story. In other words, although the different ERP effects are indicative of the engagement of at least partially non-overlapping neural systems, they do not tell us which exact cortical networks are involved in the establishing of reference, or what their relationship is to the networks known to be involved in the processing of meaning. In the last decade, language comprehension researchers have begun to use functional neuroimaging techniques (e.g., fMRI) to unravel the neuronal infrastructure of semantic, syntactic and phonological processing (e.g., Bookheimer, 2002; Friederici, 2002; Kaan and Swaab, 2002; Stowe et al., 2005, for reviews). However, with the exception of a few studies focusing on cohesion/coherence processing in discourse comprehension (Ferstl and von Cramon, 2001; Robertson et al., 2000), there has been no functional magnetic resonance imaging (fMRI) work on the neural substrate for referential processing. As a result, we know virtually nothing about how the brain subserves a core aspect of language comprehension, how people work out who's who and what's what in text or conversation.

In the present study, we used fMRI to examine the functional neuroanatomical correlates of referential processing, and to relate the cortical systems involved in establishing reference to the cortical systems recruited by semantic processing. Following up on earlier
ERP work, we focused on the processing of referentially ambiguous and referentially failing pronouns. Note that although referential ambiguity and referential failure both seem to involve disruptions of 'normal' language comprehension, such disruptions are in fact not uncommon in everyday language use (e.g., Auer, 1984), and understanding how readers deal with them is thus of a priori relevance to the study of reference resolution (e.g., Gordon et al., 1993; Sanford and Garrod, 1989). Furthermore, we know from other language comprehension research that the systems recruited by semantic and syntactic problems are also implicated in the processing of non-problematic language input. For these two reasons, we take our study to provide insights into the cortical networks involved in natural referential processing.

In our experiment, participants read sentences that were presented on a screen one word at a time, and that contained two narrative characters and one singular pronoun (cf., Table 1; see also Appendix A). This pronoun was referentially ambiguous, failing, or coherent depending on whether its gender matched both, none, or one of the characters mentioned in the sentence, respectively. In addition, referentially coherent sentences were either semantically anomalous if it contained a lexical-semantically anomalous word (downstream from the pronoun), or semantically coherent if it contained a non-anomalous control word.

The available literature suggests at least two possible scenarios that link ambiguous pronoun resolution to activity in the left inferior frontal gyrus (LIFG). First, referential ambiguity may require the language system to, from the ambiguous pronoun and onwards, actively maintain two candidate fillers for an unresolved single referential slot in working memory (e.g., Gibson, 1998). In such a scenario, the brain signature of referential ambiguity may resemble that of increased working memory load, eliciting increased activity in the LIFG (BA 44/45/47; Fletcher and Henson, 2001; Kaan and Swaab, 2002; Smith and Jonides, 1999). Second, in a recent review, Novick et al. (2005) posit a similar prediction for LIFG involvement in resolving referential ambiguity, albeit for different reasons. According to Novick et al. (2005), LIFG activations may signal resolution of the representational conflict that arises when semantic representations point towards competing interpretations, an account that makes intuitive sense with regard to referential ambiguity.

Thus, the abovementioned accounts all predict that referential ambiguity (compared to referential coherence) would lead to enhanced activation in the LIFG. This said, both accounts also predict substantial overlap for cortical networks involved in dealing with referential ambiguity and semantic anomaly, as semantic anomalies are known to elicit increased responses in the left anterior inferior frontal gyrus (LIFG, BA 45/47; e.g., Baumgaertner et al.,

Table 1

Example sentences (approximate translation from Dutch; see Appendix A for more Dutch examples)

Referential ambiguity:

Ronald told Frank that he had a positive attitude towards life. Referential failure:

Rose told Emily that he had a positive attitude towards life.

Referential coherence, semantic coherence:

Ronald told Emily that he had a positive attitude towards life.

Referential coherence, semantic anomaly:

Ronald told Emily that he had a positive potato towards life.

Critical pronouns are printed in boldface. Semantically anomalous and semantically coherent critical words are printed in italics. 
2002; Hagoort et al., 2004; Kiehl et al., 2002; Kuperberg et al., 2003).

In a third account, the processing of referential ambiguity is not necessarily linked to the LIFG at all. This account entails that ambiguous pronoun resolution requires readers to engage in problem-solving and inference procedures (e.g., Graesser et al., 1994; Greene et al., 1992). For example, readers may launch an additional search through their discourse memory (e.g., Myers and O'Brien, 1998) and infer that one of the referents is the correct one (e.g., through reasoning or decision-making). In this respect, ambiguous pronoun resolution can be considered to be a multifaceted enterprise that relies on interrelated, domain-independent executive cognitive processes, recruiting a network of prefrontal and parietal regions (e.g., Cabeza and Nyberg, 2000; Fletcher and Henson, 2001; Wagner et al., 2005). Following such an account, increased responses may be observed in brain regions that subserve knowledge-based, non-automatic inferences that require the use of general world knowledge and/or discourse information (e.g., Ferstl, in press; Ferstl and Siebörger, 2007, for reviews). These regions include medial frontal (BA 8/9/10) and parietal (BA 7/23/31) cortices (e.g., Ferstl and von Cramon, 2001, 2002; Ferstl et al., 2005; Kuperberg et al., 2006; Maguire et al., 1999; Volz et al., 2006a,b; Zysset et al., 2002, 2003), but also right lateral prefrontal (BA 8/9/ 10/46) and bilateral parietal regions (BA 39/40) involved in monitoring and evaluating of memory retrieval outcomes (e.g., Buckner and Wheeler, 2001; Wagner et al., 2005). ${ }^{1}$

For referential failure (compared to referential coherence), we predicted that the brain treats referentially failing pronouns as morpho-syntactic violations in the first instance (e.g., Osterhout and Mobley, 1995; Van Berkum et al., 2007), eliciting activity increases in left middle/superior and inferior frontal (BA 6/8/44, Hammer et al., 2007; Newman et al., 2001; Ni et al., 2000), and medial and bilateral parietal regions (BA 7/23/31/40; Kuperberg et al., 2003; $\mathrm{Ni}$ et al., 2000). However, because the pronouns as used here are 'free' in a Chomskian sense (Chomsky, 1981), there are actually alternative resolutions of the referential failure at hand. For example, readers may stick with 'blaming' the syntactic gender of the pronoun, but they may also invoke a third, unmentioned person (e.g., 'he' in "Rose told Emily that he had a positive attitude towards life" can very well be taken to refer to Rose's new boyfriend). Because these two different interpretations differ in whether or not the referents were only looked for 'within the sentence', we will refer to them as sentence-internal and sentence-external referential interpretations. In an ERP study examining referential failure, Osterhout and Mobley (1995) reported that these different interpretations may indeed elicit qualitatively different brain responses. In one of the analyses in the present study, we used the results from a post-experiment debriefing to examine whether the reliance on different resolution strategies was also reflected in differential BOLD response patterns.

In summary, the aim of the present study was to investigate the cortical networks involved in different aspects of referential processing, a crucial facet of language comprehension that has hardly been touched upon by cognitive neuroscientists. We contrasted different functional accounts of referential ambiguity that are associated with different functional neuroanatomical predictions (particularly with respect to involvement of the LIFG, a brain area typically associated with semantic processing). For referential

\footnotetext{
${ }^{1}$ Note that inference-related activity in these areas may be accompanied by activity in the LIFG (e.g., Kuperberg et al., 2006), but not necessarily so (e.g., Ferstl et al., 2001).
}

failure, we predicted, based on earlier ERP findings, that failing pronouns would elicit increased activity in brain regions involved in morpho-syntactic processing. Furthermore, we used results from a post-experiment briefing to examine potential individual differences in reference resolution strategies. Finally, the inclusion of a semantic anomaly manipulation in our design allowed us to address whether referential and semantic aspects of language comprehension draw upon common or different brain regions.

\section{Materials and methods}

\section{Participants}

Twenty-two right-handed college students (4 males, mean age 21, S.D. $=2.3$ ) participated in this study for course credits or a small monetary reimbursement. All participants were native speakers of Dutch. None of them used medication or had a history of drug abuse, head trauma, neurological or psychiatric illness. The experiment was approved by the medical ethical committee of the Amsterdam Medical Center, and informed consent was obtained from all subjects.

\section{Stimulus materials}

180 sentences (a subset of 270 sentences used by Nieuwland and Van Berkum, 2006a) were created that each described the interaction between two characters. These two narrative characters were denoted by proper names (e.g., 'John/David/Mary/Lisa'), by definite noun phrases (e.g., 'the father/son/empress/queen') or they were celebrities (e.g., 'George Bush/Bill Clinton/Madonna/Jennifer Lopez'). The referential/semantic coherence condition and semantic anomaly condition always contained 1 male and 1 female character, while the referential ambiguity and referential failure conditions both contained either 2 male or 2 female characters. All four conditions were matched on frequency and length of the words that denoted the narrative characters (celebrities were matched on frequency using Google-hits on Dutch websites). We used a range of different themes for constructing the sentences to increase the content variability of our materials, though many sentences followed the template $<$ Character $\mathrm{A}><$ verb $><$ Character $\mathrm{B}><$ while/because/ when/but/that $><$ pronoun $><$ remainder $>$.

Every sentence contained a singular pronoun ('he/she/his/her'2). In the referential coherence condition, this pronoun was referentially unambiguous as sentences from this condition always contained a uniquely identifiable antecedent. In the referential failure condition, this pronoun was referentially failing in a narrow sense, as these sentences contained no eligible sentence-internal antecedent. In the referential ambiguity condition, this pronoun was ambiguous because it could be taken to refer to either of the two narrative characters mentioned. Sentences from the semantic anomaly condition were referentially unambiguous but contained a lexicalsemantic anomaly minimally 1 word and maximally 5 words downstream from the pronoun. This anomaly was created by substituting a meaningful adjective or noun from the referentially coherent sentence type with an adjective or noun that violated the selection restrictions of the preceding verb or adjective (these semantically

\footnotetext{
${ }^{2}$ The Dutch equivalent of 'she' is 'zij', which can also mean the plural pronoun 'they'. To avoid this ambiguity, sentences containing the pronoun 'zij' were constructed so that a corresponding singular verb always preceded the pronoun, e.g., "Toen Marie Lisa opzocht keek zij.../When Marie Lisa visited looked she ....".
} 
anomalous words were matched to their control counterparts for lexical frequency and word length). As in the example sentences presented in Table 1 (see also Appendix A), all sentences from the present experiment thus differed across conditions only in the narrative characters, the critical pronouns and the semantically anomalous or control words they contained.

\section{Experimental procedure}

Before entering the scanner, participants were informed that they would be reading sentences one word at a time, presented via backprojection onto the middle of the screen and viewed by subjects using a mirror attached to the head coil. They were instructed to read the sentences attentively for comprehension and to minimize movement. No additional task demands were imposed. Each subject was presented 45 items from each condition. To counteract the transparency of presenting 180 sentences containing pronouns, we included 90 fillers sentences that also described the interaction between two characters but that did not contain any pronouns.

Four trial lists were used (each subject was randomly assigned to one of the four trial lists, so that the lists were equally distributed across subjects). For the first list, 45 items from each condition were pseudo-randomly mixed with the filler sentences such that no trial type occurred more than three times consecutively and trials of each type were matched on average list position. The other lists were derived from the first by rotating the trial types. The total of 270 sentences was divided in 6 sessions (presented in fixed-order across trial lists). Following the third session, subjects exited the scanner for a short break.

To parallel natural reading times, all words (except from the word that directly preceded the critical pronouns onwards) were presented using a variable serial visual presentation procedure (see Nieuwland and Van Berkum, 2006a). Word duration was computed as ([number of letters*30]+190), with a maximum of $430 \mathrm{~ms}$. From the word that preceded the critical pronoun onwards, every word was presented for a duration of $350 \mathrm{~ms}$, with an exception for final words, which were presented $1000 \mathrm{~ms}$. We adopted this presentation rate from an earlier ERP study (Nieuwland and Van Berkum, 2006a), where we used almost identical stimulus materials (as in that study, participants did not notice this alternation between variable and fixed word duration presentation within sentences). All inter-wordintervals were $150 \mathrm{~ms}$. After every final word, a blank (bright) screen was presented for $2 \mathrm{~s}$, which was subsequently followed by a fixation-mark. Subjects made a right button-press when the fixationmark was presented, which was followed by another blank screen for a pseudo-randomly determined period of 5, 6, 7 or $8 \mathrm{~s}$ before the first word of the next sentence was presented. During this period, subjects were instructed to fixate on the middle of the screen and await the start of the next trial. Total time-on-task was approximately $60 \mathrm{~min}$.

\section{FMRI data acquisition, preprocessing and statistical analysis}

Whole head T2*-weighted EPI-BOLD fMRI data were acquired with a $3 \mathrm{~T}$ Philips MR-scanner using an ascending slice acquisition EPI sequence (volume $\mathrm{TR}=1.96 \mathrm{~s}$; $\mathrm{TE}=30 \mathrm{~ms}$, flip angle $=90^{\circ}, 31$ axial slices, matrix size $=64 \times 64$, slice thickness $=3 \mathrm{~mm}$, slice gap $=0.5 \mathrm{~mm}, \mathrm{FOV}=224 \mathrm{~mm}$, isotropic voxel-size $=3.5 \times 3.5 \times$ $\left.3.5 \mathrm{~mm}^{3}\right)$. In addition, we acquired a structural T1-weighted MPRAGE sequence (182 coronal slices; volume $\mathrm{TR}=9.67 \mathrm{~ms}$; $\mathrm{TE}=4.6 \mathrm{~ms}$; flip angle $=8^{\circ}$; slice matrix $=256 \times 256$; slice thickness $=1.2 \mathrm{~mm}$, no slice gap; $\mathrm{FOV}=256 \mathrm{~mm}$ ). Image pre- processing and statistical analysis was performed using the SPM5 software (http://www.fil.ion.ucl.ac.uk). The functional EPI-BOLD contrast images were realigned, and the subject mean was coregistered with the corresponding structural MRI by using mutual information optimization. These images were subsequently slicetime corrected, spatially normalized, transformed into a common space (SPM5 MNI-T1 template), and spatially filtered with an isotropic 3D Gaussian kernel (10 mm FWHM). The fMRI data were analyzed statistically by using the general linear model and statistical parametric mapping. Two separate models were created for the comparisons involving the semantic and referential conditions. ${ }^{3}$ For the first model, explanatory variables included referential ambiguity, referential failure and referential coherence, and also the intersentence-interval fixation period (as a non-reading baseline). All three referential conditions were modeled from the onset of the corresponding critical pronouns up to the onset of sentence-final words (the referential coherence variable also included the referentially and semantically coherent part of the sentences containing semantic anomalies downstream; post-hoc analyses showed that excluding this sentence part led to the same pattern of results as reported below), whereas inter-sentence interval was modeled from the onset of the fixation cross up to the onset of every sentence-first word. For the second model, explanatory variables included semantic coherence and semantic anomaly, both ranging from the onset of the critical word up to the onset of the fixation cross. In both models, effects of no-interest included one regressor that pooled all other sentence-reading time windows (filler sentences, critical sentence parts up to the critical pronouns), and additional regressors for session and subject effects. The explanatory variables in each model were temporally convolved with the canonical hemodynamic response function along with its temporal derivative (Friston et al., 1998) provided by SPM5. For the statistical analysis, parameter estimates for the explanatory variables were generated for each subject. Subsequently, only the parameters involving the critical sentence parts and the parameter for the intersentence interval were subjected to a second-level random effects analysis with nonsphericity correction for correlated repeated measures.

The following linear contrasts (and their reverse counterparts) were specified: referential ambiguity $>$ referential coherence, referential failure $>$ referential coherence, semantic anomaly $>$ semantic coherence, referential ambiguity $>$ referential failure. The results of the random effects analyses were thresholded at $P=0.001$ (uncorrected) and the cluster-size statistics were used as the test statistic. Only clusters at $P \leq 0.05$ (corrected for multiple comparisons using the false discovery rate, FDR; Genovese et al., 2002) were considered significant. When substantial activation clusters fell in prior regions of interest ${ }^{4}$ but did not survive this threshold, cluster-

\footnotetext{
${ }^{3}$ The reason for using separate models is as follows: because referential ambiguity is known to elicit sustained effects in the ERP waveform (e.g., Nieuwland and Van Berkum, 2006a), we wanted to model the effect of referential ambiguity within a relatively large time window from the critical pronouns onward. However, because the semantically anomalous and coherent control words occurred sometimes only a few words downstream from the critical pronouns, we set up a separate model for the semantic conditions to avoid modeling data twice within the same analysis.

${ }^{4}$ Prior regions of interest were defined as those Brodmann's areas for which we predicted possible activation differences across conditions in the introduction, and that also showed significant effects of condition type in a full-factorial model (that included all our conditions of interest, using a cluster-level FDR-correction at $P \leq 0.05$ ).
} 
level FDR-correction was applied to a subset of voxels following small volume correction $(\mathrm{SVC}$, spherical radius $=10 \mathrm{~mm}$; these settings were chosen because they roughly match the spatial localization precision in fMRI data, e.g., Brett et al., 2002; Petersson et al., 1999). All local maxima are reported as MNI coordinates (Evans et al., 1993). Approximate Brodmann's areas were estimated from converted MNI coordinates (http://www.mrc-cbu.cam.ac.uk/ Imaging/mnispace.html), using the Talairach Daemon Client (http:// ric.uthscsa.edu/projects/talairachdaemon.html).

\section{Results}

We first investigated the contrasts involving referential ambiguity, referential failure and semantic anomaly compared to their coherent counterparts. The corresponding statistical results are presented in Table 2. As visible from Fig. 1A, referential ambiguity (ambiguity $>$ coherence; Fig. 1A, Table 2A) was associated with greater activation in a set of regions that included medial frontal gyrus (BA 10), right superior frontal cortex (BA 8/9), medial parietal cortices (precuneus, BA 7/31), and bilateral inferior parietal regions (BA 39). Referential failure (failure $>$ coherence) was associated with a significantly activated set of regions (Fig. 1B, Table 2B) that also included medial parietal regions (precuneus, BA 7) and bilateral inferior parietal regions (BA 7/ 39/40), but no medial frontal regions. In line with earlier findings, semantic anomaly (anomaly>coherence) was associated with significantly enhanced activity in left inferior frontal gyrus (BA 44/45/47; Fig. 1C, Table 2C), and to some extent its right hemisphere counterpart.

For the abovementioned comparisons, we also tested the reverse contrasts to examine which brain regions showed a relative decrease in activity following referential ambiguity, referential failure and semantic anomaly compared to their coherent counterparts. For referential ambiguity, relative decreases occurred in bilateral inferior frontal gyrus (BA 44/45/47; Fig. 1E, Table 2E). For referential failure, a relative decrease was observed in a left medial temporal region that entailed the parahippocampal gyrus (Fig. 1F, Table 2F). For semantic anomaly, relative decreases occurred in medial frontal regions (BA 10/11/25, including the anterior cingulate cortex and the caudate nucleus), medial parietal regions (precuneus/PCC, BA 7/ 30/31), and right superior frontal cortex (BA 8/9; Fig. 1G, Table 2G).

To examine which brain areas were differentially modulated by the two different referential problems, we also made a direct comparison between referential ambiguity and referential failure. Compared to referential failure, referential ambiguity was associated with enhanced activity in medial frontal cortex (BA 9/10; Fig. 1D, Table 2D) and to some extent in medial parietal cortex (BA 31), while it was associated with a relative decrease of activity in posterior parts of bilateral inferior frontal gyrus (BA 44/45; Fig. 1H, Table 2H).

Notes to Table 2:

$Z$-values correspond to the local maxima in the relevant cluster (multiple local maxima are reported when they are more than $8 \mathrm{~mm}$ apart). Cluster size and cluster-level statistical significance are given in the far right column.

*Cluster-level significance (FDR-correction at $P \leq 0.05$ ): $* * * P \leq 0.001$, ${ }^{*} P \leq 0.01,{ }^{*} P \leq 0.05$.

${ }^{\wedge}$ Cluster-level significance (FDR-correction at $\left.P \leq 0.05\right)$ after small volume correction (SVC) with a $10 \mathrm{~mm}$ radius spherical region around the reported coordinates: ${ }^{\wedge} \wedge P \leq 0.005, \wedge P \leq 0.01$.
Table 2

MNI-coordinates and approximate Brodmann's area (BA) corresponding to the brain regions that showed significant differential effects in the 8 pair-wise comparisons (A to $\mathrm{H}$ )

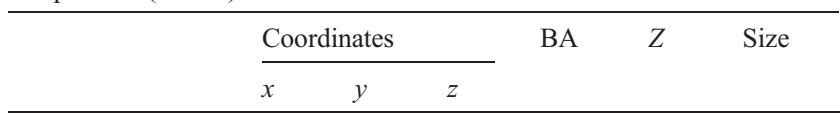

(A) Referential ambiguity $>$ Referential coherence

$\begin{array}{lrrrlll}\text { Medial frontal } & -6 & 66 & -2 & 10 & 4.31 & 529^{* *} \\ & 2 & 64 & 20 & 10 & 3.45 & 60^{\wedge} \\ \text { Superior frontal R } & 28 & 28 & 44 & 8 / 9 & 4.09 & 347^{*} \\ \text { Medial parietal } & -6 & -62 & 30 & 7 / 31 & 5.31 & 2576^{* * *} \\ & -10 & -64 & 44 & 7 & & \\ \text { Lateral parietal L } & -5 & -64 & 48 & 7 & & \\ \text { Lateral parietal R } & 50 & -68 & 30 & 39 & 4.10 & 498^{* *} \\ & & -62 & 30 & 39 & 4.09 & 619^{* *}\end{array}$

(B) Referential failure $>$ Referential coherence $\begin{array}{llll}\text { Medial parietal } & 4 & -64 & 46\end{array}$ Lateral parietal L $\quad-40 \quad-60 \quad 50$ $\begin{array}{lllll}-48 & -52 & 48 & 39 / 40 & 3.83\end{array}$ $\begin{array}{lrrrll} & -54 & -54 & 42 & 39 / 40 & 3.66 \\ \text { Lateral parietal R } & 52 & -62 & 42 & 39 & 4.17\end{array}$ $\begin{array}{lllllll}\text { Middle frontal L } & -42 & 10 & 54 & 6 / 8 & 3.76 & 67^{\wedge}\end{array}$

(C) Semantic anomaly $>$ Semantic coherence

\begin{tabular}{lrrrrrr} 
Inferior frontal L & -44 & 24 & 0 & $45 / 47$ & 4.17 & $722^{* *}$ \\
& -46 & 32 & 8 & 45 & & \\
& -52 & 14 & 18 & 44 & & \\
Inferior frontal R & 50 & 32 & 4 & 45 & 3.81 & $111^{\wedge}$ \\
\multicolumn{7}{c}{ (D) Referential ambiguity $>$ Referential failure } \\
Medial frontal & -2 & 62 & 24 & $9 / 10$ & 4.63 & $1375^{* * *}$ \\
& -2 & 50 & -6 & 10 & 4.37 & \\
Medial parietal & -8 & 62 & -2 & 10 & 3.74 & \multirow{2}{*}{$168^{\wedge \wedge}$}
\end{tabular}

(E) Referential ambiguity $<$ Referential coherence

$\begin{array}{lrrrlll}\text { Inferior frontal L } & -42 & 28 & -2 & 45 / 47 & 4.26 & 407^{*} \\ & -50 & 26 & 18 & 45 & & \\ \text { Inferior frontal R } & 40 & 32 & -8 & 45 / 47 & 4.16 & 518^{* *} \\ & 40 & 22 & 12 & 45 & & \\ & 50 & 18 & 18 & 44 / 45 & & \end{array}$

(F) Referential failure $<$ Referential coherence

Medial temporal L $\quad-30 \quad-12 \quad-14 \quad 20 / 21 \quad 4.46 \quad 306^{*}$

(G) Semantic anomaly $<$ Semantic coherence

\begin{tabular}{lrrrlll} 
Medial frontal & 4 & 60 & -10 & $10 / 11$ & 3.98 & $304^{*}$ \\
& -4 & 18 & -14 & 25 & 3.95 & $363^{*}$ \\
& 0 & 10 & -10 & 25 & 3.79 & \\
Superior frontal R & 6 & 22 & -20 & 25 & 3.61 & \\
Medial parietal & -8 & 30 & 46 & $8 / 9$ & 4.82 & $577^{* *}$ \\
& 8 & -64 & 22 & 31 & 4.56 & $3231^{* * *}$ \\
& -12 & -62 & 34 & 7 & 4.40 & \\
(H) Referential ambiguity $<$ Referential failure & & & \\
Inferior frontal L & -42 & 24 & 18 & $44 / 45$ & 3.72 & $167^{\wedge \wedge}$ \\
Inferior frontal R & 38 & 24 & 18 & $44 / 45$ & 3.86 & $104^{\wedge}$ \\
\hline
\end{tabular}


(A)
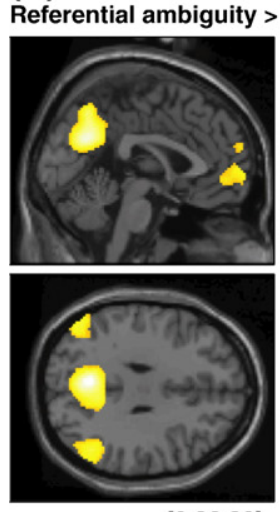

(B)

[0 26 30]

Referential failure $>$ Referential coherence
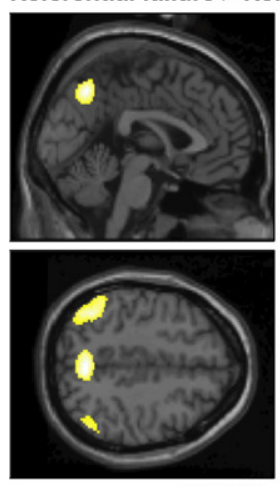

[0 8 46]

(C)

Semantic anomaly > Semantic coherence
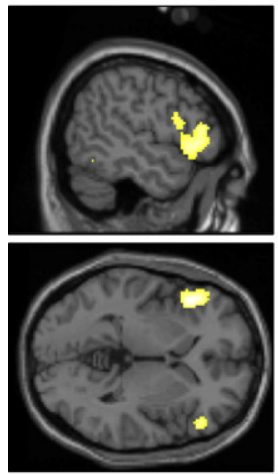

$[-50,32,0]$

(D)

Referential ambiguity > Referential failure
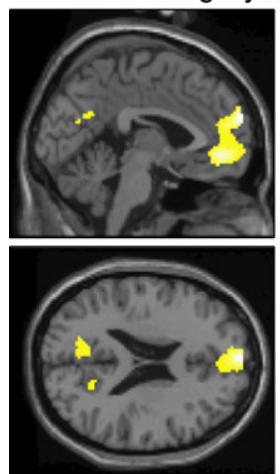

[-2 60 22]

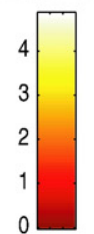

(E)

Referential ambiguity $<$ Referential coherence
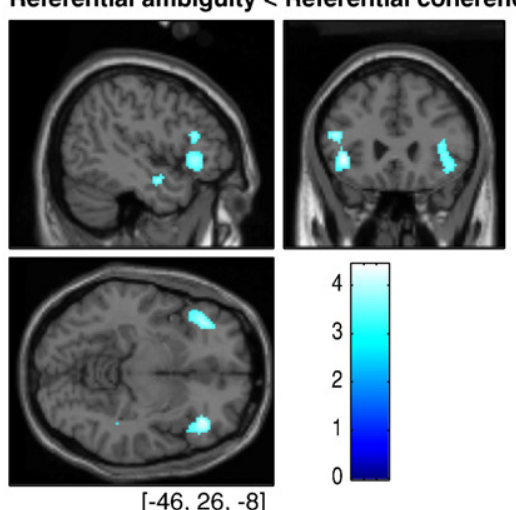

(F)

Referential failure < Referential coherence
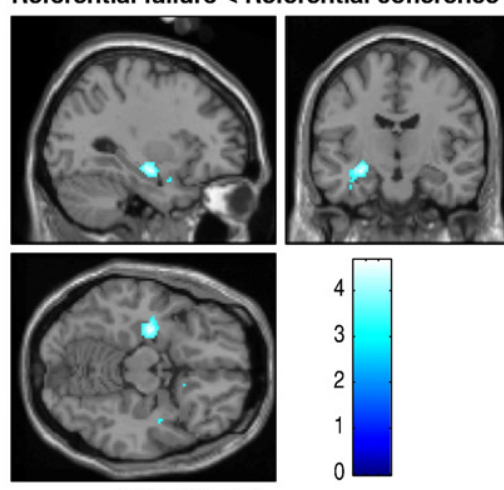

(G)

Semantic anomaly < Semantic coherence
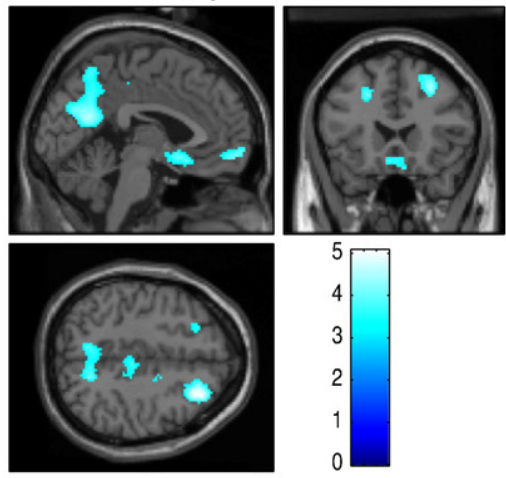

(H)

$[-2,22,46]$

Referential ambiguity < Referential failure
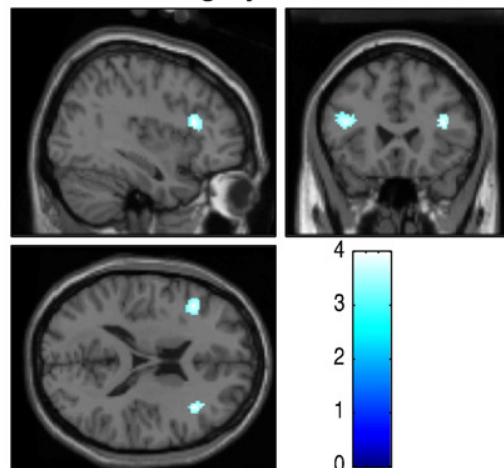

4
3
2
1
0

$[38,24,18]$

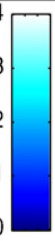



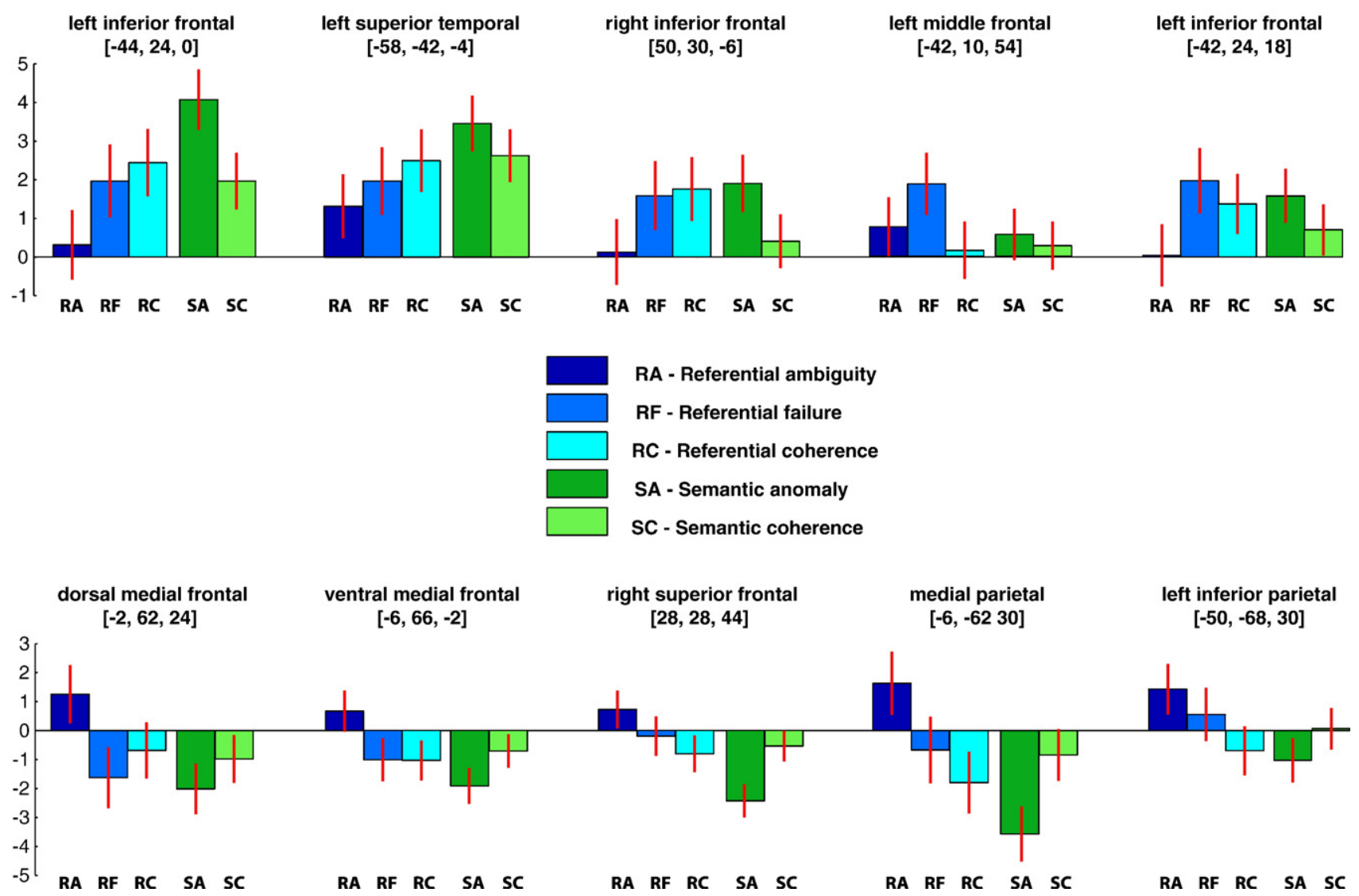

Fig. 2. Hemodynamic responses of each referential and semantic condition compared to fixation ( $y$-axis represents the corresponding contrast estimates, with red vertical bars indicating the $90 \%$ confidence intervals) for a selection of brain regions that differentiated between conditions in the pair-wise comparisons (additional graphs are plotted for left superior temporal gyrus). The upper graph represents the brain regions that were generally more active during referential and semantic conditions compared to fixation. The lower graph represents the brain regions that were generally less active during referential and semantic conditions compared to fixation. Note that we do not wish to make claims about any of the conditions compared to the fixation condition: the sole purpose of this figure is to assist the reader in surveying the patterns of relative activations and deactivations, across all relevant conditions and brain regions.

As evident from Figs. 1A, C, E and G, BOLD responses to referential ambiguity and semantic anomaly revealed opposite patterns in different regions throughout prefrontal and parietal cortex. Activity in medial and lateral parietal, medial frontal and right superior frontal cortices increased following referential ambiguity, but decreased following semantic anomaly. In contrast, an opposite pattern was observed in bilateral inferior frontal regions. To explore whether problems with referential and semantic interpretation differentially modulate brain activity in these regions compared to a relatively passive task, we specified separate contrasts for each referential and semantic condition compared to the inter-sentence fixation period. Fig. 2 displays each of these contrasts for a selection of brain regions that differentiated between conditions in the pair-wise comparisons (additional contrasts are plotted for left superior temporal gyrus). As can be seen from Fig. 2, referential ambiguity had only a very marginal effect in brain regions that are generally more active during sentence reading compared to fixation (upper graphs), and was associated with increased activity in brain regions that were generally less active during sentence reading compared to fixation (lower graphs). In contrast, semantic anomaly led to an opposite pattern of results for most of these regions.

Finally, we addressed whether the adoption of different solutions for resolving referentially failing pronouns was reflected in differential BOLD response patterns. In a post-experiment debriefing, subjects were presented 3 example sentences from the referential failure condition, and were asked to indicate how they interpreted the failing pronouns, and whether they had consistently used this type of interpretation throughout the experiment. Seven subjects (approximately equally distributed across the four versions of the experiment) indicated to have consistently adopted a thirdperson, sentence-external interpretation (whereas no subject indicated to have used such a strategy for resolving referential ambiguity), while the other subjects indicated that they had consistently used a sentence-internal interpretation (i.e., they took the referentially failing pronoun as having an erroneous gender but referring to one of the characters mentioned in that sentence). To explore the neural correlates of these different resolution strategies, we entered the subject-level results from the original referential failure contrast (referential failure $>$ coherence) into a new, between-group contrast

Fig. 1. Pair-wise comparisons across all 22 subjects (thresholded at $P \leq 0.001$ uncorrected, images are presented according to neurological convention, colorscales reflect the corresponding $T$-values). MNI-coordinates (reported below each subset of images) were chosen as to maximize the visibility of the dominant effects for each comparison. 
(A) Sentence external > Sentence internal
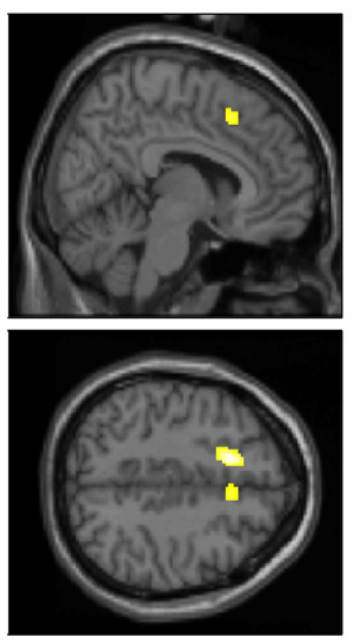

$[82046]$
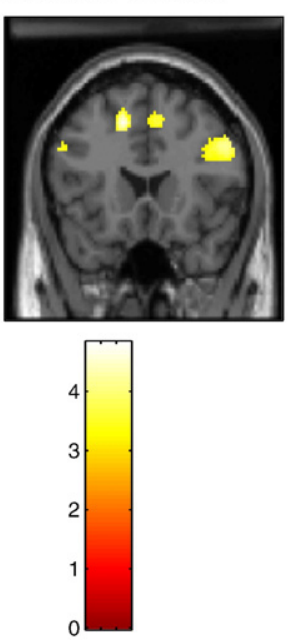

0 L...
(B) Sentence external $<$ Sentence internal
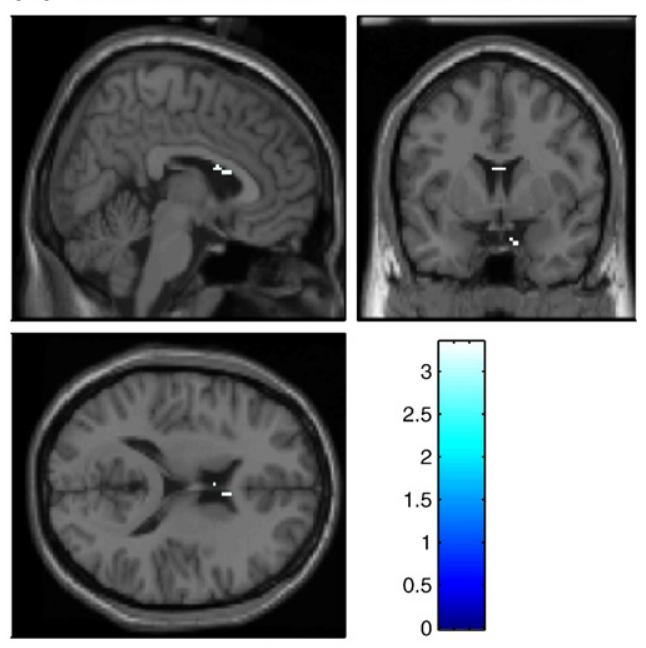

[2 4 18]

Fig. 3. Pair-wise comparisons of BOLD responses (thresholded at $P \leq 0.001$ uncorrected) to referential failure for subjects who had made sentence-external anaphoric inferences versus sentence-internal anaphoric inferences.

(sentence-external $>$ sentence-internal). This contrast (thresholded at $P \leq 0.001$ uncorrected, cluster-level FDR corrected at $P \leq 0.05$ ) yielded two large clusters of activity ${ }^{5}$ (Fig. 3A): the first cluster was located in the left medial superior frontal gyrus (BA 8; $P=0.073$, containing two local maxima at $[-14,18,48]$ and $[-18,32,36])$. The second cluster was located in the right middle frontal gyrus (dorsolateral BA 9/46, $P=0.002$, containing three local maxima at $[52,26,28],[50,16,34]$ and $[38,16,34])$. The reverse contrast (sentence-external $<$ sentence-internal) yielded no significantly activated clusters (Fig. 3B).

\section{Discussion}

The objective of the present study was to investigate the functional neuroanatomical correlates of referential processing. We compared event-related BOLD-fMRI responses to sentences containing referentially ambiguous (e.g., "Ronald told Frank that he..."), referentially failing pronouns (e.g., "Rose told Emily that he...") or referentially coherent pronouns (e.g., "Frank told Emily that he..."). To provide a benchmark for these results, we also compared responses to sentences containing semantically anomalous or semantically coherent words (e.g., "Ronald told Emily that she had a positive potato/attitude..."). This allowed us to examine to what extent semantic and referential aspects of language comprehension recruit common or distinct neural circuits. In the following paragraphs, we will recap our main findings and address their implications.

\section{Referential ambiguity and medial prefrontal regions}

Following referential ambiguity, we observed activation increases in medial and bilateral parietal, medial frontal and right

\footnotetext{
${ }^{5}$ Additional activations were located in the posterior cingulate gyrus (BA $31,[-12,-54,24]$, voxel-level $P=0.065$, voxel-level FDR corrected at $P \leq 0.05$ ), middle temporal gyrus (BA 21, $[-58,-14,-12]$, voxel-level $P=0.085$ ), and also right medial frontal gyrus (BA 8, $[8,20,46]$, voxel-level $P=0.085)$.
}

superior frontal regions. This activation pattern suggests that referential ambiguous pronouns required readers to engage in problem-solving (i.e., inference procedures, Ferstl, in press; Ferstl and Siebörger, 2007) in order to establish reference and build a coherent model of the text (e.g., Graesser et al., 1994; Greene et al., 1992). Furthermore, as referential ambiguity did not elicit increases in the LIFG, our results suggest that the processing consequences of referential ambiguity are qualitatively different from those imposed by verbal working memory manipulations (e.g., Fletcher and Henson, 1999) or conflicting semantic representations (e.g., Novick et al., 2005). ${ }^{6}$

The most distinctive brain signature of referential ambiguity was the activation increases in dorsal and anterior/ventral medial frontal cortices (see Figs. 1A and D). Because referentially ambiguous pronouns also elicit a sustained frontally-distributed negative shift in the ERP (e.g., Nieuwland and Van Berkum, 2006a), we speculate that at least some of the neural generators of this ERP effect are located in the reported dorsal and anterior/ ventral medial prefrontal regions. Although there is as yet no coherent account of the exact functional significance of these anterior prefrontal brain regions (BA10, e.g., Burgess et al., 2005; Ramnani and Owen, 2004), dorsal medial frontal regions have been implicated in making controlled, higher-order inferences to establish coherence during discourse comprehension (e.g., Ferstl and von Cramon, 2001), and anterior/ventral medial prefrontal regions have been related to making evaluative judgments (e.g.,

\footnotetext{
${ }^{6}$ Although dealing with referential ambiguity did not elicit LIFG activation increases, this is not to say that the LIFG is not involved in referential analysis at all, because referential analysis necessarily takes place also in referentially coherent sentences. In fact, one could speculate whether sentences that require pronoun resolution (and require more binding operations; e.g., Hagoort, 2005) engage more LIFG processes than sentences that do not require pronoun resolution. In the current study, we were not able to address this issue because our filler sentences (that did not contain pronouns) were not properly matched to the critical sentences, but initial results on reflexive binding (Santi and Grodzinsky, in press) suggest this possibility.
} 
Goel and Dolan, 2003; Petersson et al., 2003; Zysset et al., 2002, 2003) and decision-making (e.g., Volz et al., 2006b). Thus, consistent with what our subjects had indicated in the postexperiment debriefing, the present medial prefrontal activations may reflect that subjects made an evaluation or choice between the two referential candidates (i.e., an anaphoric inference, Greene et al., 1992) in order to establish a referentially coherent interpretation. $^{7}$

\section{Referential failure and sentence-external anaphoric inferences}

Also consistent with our predictions, referentially failing pronouns elicited increased BOLD responses in medial and bilateral parietal, and left middle frontal brain regions (e.g., Hammer et al., 2007; Kuperberg et al., 2003; Newman et al., 2001; $\mathrm{Ni}$ et al., 2000), supporting the notion that readers initially ascribed referential failure to a problem with the morpho-syntactic gender of the pronoun (e.g., Osterhout and Mobley, 1995; Van Berkum et al., 2007).

An additional interesting finding resulted from our split-group analysis: whereas most readers took failing pronouns as morphosyntactically incorrect and as referring to one of the narrative characters mentioned in the sentence, some participants had indicated in the post-experiment debriefing to have consistently invoked a third, unmentioned character. These sentence-external inferences were accompanied by additional increases in medial frontal and right dorsolateral brain regions (Fig. 3A). These regions have been associated with a range of cognitively demanding tasks (e.g., Duncan and Owen, 2000; Fletcher and Henson, 2001; Ridderinkhof et al., 2004). Interestingly, they have also been implicated in making causal inferences in order to plausibly link sentences together (e.g., Kuperberg et al., 2006). When readers make causal inferences, they elaborate on what may have happened in the described scenario but was not explicitly stated in the text (e.g., Singer, 1994; Van den Broek, 1994). Similarly, sentence-external anaphoric inferences may require readers to infer that the two narrative characters were already engaged in a conversation about a third person, or perhaps that some specific event took place that caused the two narrative characters to engage in conversation. In this respect, the similarities between the present results and those reported by Kuperberg et al. (2006) may reflect that both types of inferences require readers to engage in elaborative processing in order to make sense of the described situation.

\footnotetext{
${ }^{7}$ Note that we have as yet refrained from relating our findings for referential ambiguity to results obtained with other linguistic ambiguity manipulations. Our results tie in with those from a study by Chan and colleagues (2004), who used a word-generation paradigm, and reported that isolated, lexically ambiguous words (compared to unambiguous words) elicited relative activation decreases in the LIFG, but relative increases in medial frontal cortex. In contrast, both syntactic and lexical ambiguity have been reported to enhance activity in LIFG regions when examined with sentence comprehension paradigms (e.g., Fiebach et al., 2004; Mason et al., 2003; Rodd et al., 2005). However, lexical ambiguity may also invoke semantic implausibility depending on the meaning that is pursued (e.g., "there was thyme/time and sage...", Rodd et al., 2005), and syntactically ambiguous sentences often contain unusual constructions (e.g., "The experienced soldiers warned about the dangers before the midnight raid.", see Mason et al., 2003, for discussion). Constrained by the limited temporal resolution of fMRI, it may be difficult in such paradigms to dissociate syntactic/semantic complexity or garden-path effects from those of lexical or syntactical ambiguity.
}

Referential and semantic processing modulates activity in common regions, but in opposite directions

Consistent with results from similar studies (e.g., Baumgaertner et al., 2002; Hagoort et al., 2004; Kiehl et al., 2002; Kuperberg et al., 2003), semantic anomalies elicited increased BOLD responses in left and right inferior frontal gyrus (BA 44/45/47), possibly reflecting the increased amount of semantic processing (e.g., Badre and Wagner, 2002; Bookheimer, 2002, for reviews) needed to build a situation model from semantically unexpected or implausible input. In line with earlier ERP research (e.g., Nieuwland and Van Berkum, 2006a; Van Berkum et al., 2007), the present findings thus show that the language comprehension system relies on different neural mechanisms to deal with referential ambiguity, referential failure and semantic anomaly. Moreover, a closer examination of relative activation increases and decreases across different brain regions for all conditions revealed an intriguing pattern of results. Bilateral and medial parietal regions showed relative increases following both referential problems (see Figs. 1A and B), but a relative decrease following semantic anomaly (see Fig. 1G). In contrast, bilateral inferior prefrontal regions showed an almost exactly opposite pattern: relative increases following semantic anomaly (Fig. 1C), but relative decreases following referential ambiguity (Fig. 1E).

Although the relative decrease in the LIFG following referential failure was not significant, this pattern of results is very similar to the pattern reported for semantic and morpho-syntactic violations by Kuperberg et al. (2003). In the Kuperberg et al. study, subjects made faster plausibility judgments to morpho-syntactic violations than to correct words or semantic violations, and since difficult tasks elicit stronger decreases in bilateral and medial parietal regions (e.g., Gusnard and Raichle, 2001; Shulman et al., 1997), Kuperberg et al. (2003) suggested that morpho-syntactic violations elicited relative activation increases in these parietal regions because these violations required less attentional resources. Although the present results indeed closely resemble those reported by Kuperberg et al. (2003), our exact findings do not support the latter interpretation, because it seems unlikely that referentially problematic pronouns in the present study actually required less attentional resources than coherent pronouns. Furthermore, we also observed that superior regions of the left middle frontal cortex (BA 6/8) showed distinctive activation increases following referential failure (see also Hammer et al., 2007).

If not the allocation of attentional resources, then what does the differential modulation of parietal and lateral prefrontal regions reflect? Consistent with the presumed role of medial and bilateral parietal regions in episodic memory processing and the monitoring of internal representations (e.g., Wagner et al., 2005), it is possible that the activations in these regions reflect the reprocessing of the episodic memory trace of the sentence when readers resolve a referentially problematic situation (e.g., Myers and O'Brien, 1998). Such a reprocessing account may also explain why morphosyntactic number violations elicit similar parietal activation patterns (e.g., Kuperberg et al., 2003). Because dealing with semantic anomalies hinges less on reprocessing or revision of the episodic memory trace of the sentence, but involves the construction of a mental model from the sentence as it was stated (that is implausible with regard to world knowledge), semantic anomalies recruit inferior prefrontal brain regions associated with semantic processing (e.g., Bookheimer, 2002). Our results may thus reflect the dynamic recruitment of semantic and episodic processing to resolve semantically or referentially problematic situations. 
Although previous studies have reported that coherencebuilding processes are not necessarily accompanied by LIFG activations (see also Ferstl and von Cramon, 2001), we can only speculate why referential ambiguity was associated with relative decreases in the LIFG. These patterns may reflect the reduced amount of semantic processing when readers are faced with a referentially ambiguous situation that hinders the successful semantic integration or binding of incoming information. Consistent with this notion, referentially coherent pronouns elicit gamma power increases in the EEG frequency spectrum, whereas referentially ambiguous and failing pronouns both elicit gamma power decreases (e.g., Van Berkum et al., 2004), possibly signaling the successful versus problematic binding of incoming information into a coherent mental representation (e.g., Tallon-Baudry and Bertrand, 1999). On the other hand, our results may also partly reflect reciprocal attenuation between lateral prefrontal and parietal regions (e.g., Greicius et al., 2003). Future research will need to address the functional connectivity patterns to uncover interactions between the neural networks involved in different aspects of language comprehension (e.g., Petersson et al., 2006).

\section{Conclusions}

Taken together, our results show that referential ambiguity, referential failure and semantic anomaly elicit qualitatively different brain responses during sentence comprehension. Referentially ambiguous pronouns selectively recruited medial prefrontal regions, suggesting that readers made evaluative judgments about the referential candidates in order to construct a referentially coherent sentence interpretation. Referentially failing pronouns elicited activation increases in brain regions associated with morphosyntactic processing (notably, parietal and middle frontal regions), and elicited additional activations associated with elaborative inferencing if readers took failing pronouns to refer to unmentioned entities. Our results also showed that semantic and referential aspects of language comprehension modulate activity in overlapping brain regions in opposite directions, perhaps reflecting the dynamic recruitment of semantic and episodic processing to resolve semantically or referentially problematic situations.

Because our results show that referential analysis during sentence comprehension draws upon brain regions beyond the 'traditional' temporal-frontal language network, these results also have implications for neurocognitive models of language comprehension. Current neurocognitive models (e.g., Friederici, 2002; Hagoort, 2005; Jung-Beeman, 2005) focus on different aspects of language comprehension, but none of them seems to have the necessary machinery to deal with the establishing of reference. A complete neurocognitive account of language comprehension needs to address not just how we parse a sentence and combine the meaning of the individual words, but also how we determine who's who and what's what during sentence and discourse comprehension.

\section{Acknowledgments}

We gratefully thank Steven Scholte for his technical advice, Tessa Dekker and Sietske Kleibeuker for help in data collection, and Gina Kuperberg, and Evelyn Ferstl for valuable comments on an earlier draft of this manuscript. This research was supported by an NWO Innovation Impulse Vidi grant to JVB. MSN is currently funded by a Rubicon grant from the Netherlands Organisation for Scientific Research (NWO).

\section{Appendix A}

Example sentences across the different experimental conditions: (a) referential ambiguity, (b) referential failure, (c) referential coherence and semantic control, (d) referential coherence and semantic anomaly, $(\sim)$ approximate English translation (referentially ambiguous version, showing both the semantically anomalous and semantically coherent word). Critical pronouns are printed in boldface. Semantically anomalous and semantically coherent critical words are printed in italics.

1a. Elco kreeg ruzie met Emil toen hij smeuïge roddels vertelde.

1b. Paula kreeg ruzie met Marjolein toen hij smeuïge roddels vertelde.

1c. Paula kreeg ruzie met Emil toen hij smeuïge roddels vertelde.

1d. Paula kreeg ruzie met Emil toen hij smeuïge pennen vertelde.

$1 \sim$. Elco got into an argument with Emil when he told juicy pens/gossip.

2a. Dolf groet Roland altijd wanneer hij de stille studiezaal binnenkomt.

2b. Eva groet Monique altijd wanneer hij de stille studiezaal binnenkomt.

2c. Eva groet Roland altijd wanneer hij de stille studiezaal binnenkomt.

2d. Eva groet Roland altijd wanneer hij de stille paraplu binnenkomt.

$2 \sim$. Dolf always greets Roland as he enters the quiet umbrella/ study hall.

3a. Isaak geeft vaak af op Tjeerd wanneer zijn strenge baas in de buurt is.

3b. Isaak geeft vaak af op Marleen wanneer zijn strenge baas in de buurt is.

3c. Karin geeft vaak af op Marleen wanneer zijn strenge baas in de buurt is.

3d. Isaak geeft vaak af op Marleen wanneer zijn strenge boot in de buurt is.

$3 \sim$. Isaak often runs Tjeerd down when his strict boat/boss is around.

4a. Mattijs vroeg Chiel omdat hij graag met slimme kindjes werkt.

4b. Elsa vroeg Nina omdat hij graag met slimme kindjes werkt.

4c. Elsa vroeg Chiel omdat hij graag met slimme kindjes werkt.

4d. Elsa vroeg Chiel omdat hij graag met slimme huizen werkt.

$4 \sim$. Mattijs asked Chiel because he likes to work with smart houses/children.

5a. De zakenman riep de dealer net toen hij de dure club uit liep.

5b. De actrice riep de huisvrouw net toen hij de dure club uit liep.

5c. De actrice riep de dealer net toen hij de dure club uit liep.

5d. De actrice riep de dealer net toen hij de dure hand uit liep.

$5 \sim$. The businessman called the dealer just as he walked out of the expensive hand/club.

6a. Toen Beyonce Madonna tegenkwam had zij net een ongelukje bij de kapper gehad. 
6b. Toen Eminem Prince tegenkwam had zij net een ongelukje bij de kapper gehad.

6c. Toen Beyonce Prince tegenkwam had zij net een ongelukje bij de kapper gehad.

6d. Toen Beyonce Prince tegenkwam had zij net een ongelukje bij de angst gehad.

6 . When Beyonce met Madonna she had just had a little accident at the fear/barber.

\section{References}

Auer, J.C.P., 1984. Referential problems in conversation. J. Pragmat. 8, $627-648$.

Badre, D., Wagner, A.D., 2002. Semantic retrieval, mnemonic control, and prefrontal cortex. Behav. Cogn. Neurosci. Rev. 1 (3), 206-218.

Baumgaertner, A., Weiller, C., Buchel, C., 2002. Event-related fMRI reveals cortical sites involved in contextual sentence integration. NeuroImage 16 (3), 736-745.

Bookheimer, S., 2002. Functional MRI of language: new approaches to understanding the cortical organization of semantic processing. Annu. Rev. Neurosci. 25, 151-188.

Brett, M., Johnsrude, I.S., Owen, A.M., 2002. The problem of functional localization in the human brain. Nat. Rev., Neurosci. 3, 243-249.

Buckner, R.L., Wheeler, M.E., 2001. The cognitive neuroscience of remembering. Nat. Rev., Neurosci. 2 (9), 624-634.

Burgess, P.W., Simons, J.S., Dumontheil, I., Gilbert, S.J., 2005. The gateway hypothesis of rostral prefrontal cortex (area 10) function. In: Duncan, J., Phillips, L., McLeod, P. (Eds.), Measuring the Mind: Speed, Control, and Age. University Press, Oxford, pp. 215-246.

Cabeza, R., Nyberg, L., 2000. Imaging cognition II: an empirical review of 275 PET and fMRI studies. J. Cogn. Neurosci. 12 (1), 1-47.

Carreiras, M., Clifton Jr., C., 2004. The On-Line Study of Sentence Comprehension: Eyetracking, ERPs and Beyond. Psychology Press, New York.

Chan, A.H.D., Liu, H.L., Yip, V., Fox, P.T., Gao, J.H., Tan, L.H., 2004. Neural systems for word meaning modulated by semantic ambiguity. NeuroImage 22 (3), 1128-1133.

Chomsky, N., 1981. Lectures on Government and Binding: The Pisa Lectures. Holland: Foris Publications 7th ed, Berlin and New York: Mouton de Gruyter, 1993.

Duncan, J., Owen, A.M., 2000. Common regions of the human frontal lobe recruited by diverse cognitive demands. Trends Neurosci. 23 (10), 475-483.

Evans, A.C., Collins, D.L., Mills, S.R., Brown, E.D., Kelly, R.L., Peters, T.M., 1993. IEEE Conference Record, Nuclear Science Symposium, and Medical Imaging Conference (Inst. Electr. Electron. Eng., San Francisco), pp. 1813-1817.

Ferstl, E.C., in press. The functional neuronatomy of text comprehension: What's the story so far? In: Schmalhofer, F., Perfetti, C.A. (Eds.), Higher Level Language Processes in the Brain: Inference and Comprehension Processes. Mahwah: Lawrence Erlbaum.

Ferstl, E.C., Siebörger, F.Th., 2007. Neuroimaging studies of coherence processes. In: Schwarz-Friesel, M., Consten, M., Knees, M. (Eds.), Anaphors in Text: Cognitive, Formal and Applied Approaches to Anaphoric Reference, $($ SLCS $=$ Studies in Language Companion Series Vol. 86). Benjamins, Amsterdam, NL, pp. 225-240.

Ferstl, E.C., von Cramon, D.Y., 2001. The role of coherence and cohesion in text comprehension: an event-related fMRI study. Cogn. Brain Res. 11 (3), 325-340.

Ferstl, E.C., von Cramon, D.Y., 2002. What does the fronto-medial cortex contribute to language processing: coherence or theory of mind? NeuroImage 17, 1599-1612.

Ferstl, E.C., Rinck, M., von Cramon, D.Y., 2005. Emotional and temporal aspects of situation model processing during text comprehension: an event-related fMRI study. J. Cogn. Neurosci. 17 (5), 724-739.
Fiebach, C.J., Vos, S.H., Friederici, A.D., 2004. Neural correlates of syntactic ambiguity in sentence comprehension for low and high span readers. J. Cogn. Neurosci. 16 (9), 1562-1575.

Fletcher, P.C., Henson, R.N.A., 2001. Frontal lobes and human memory-Insights from functional neuroimaging. Brain 124, 849-881.

Frege, G., 1892. On Sense and Nominatum. In: Martinich, A.P. (Ed.), The Philosophy of Language 2nd ed, New York: Oxford University Press, 1990 , pp. $190-202$.

Friederici, A.D., 2002. Towards a neural basis of auditory sentence processing. Trends Cogn. Sci. 6, 78-84.

Friston, K.J., Fletcher, P., Josephs, O., Holmes, A., Rugg, M.D., Turner, R., 1998. Event-related fMRI: characterizing differential responses. NeuroImage 7 (1), 30-40.

Garnham, A., 2001. Mental Models and the Interpretation of Anaphora. Taylor and Francis, Philadelphia.

Genovese, C.R., Lazar, N.A., Nichols, T., 2002. Thresholding of statistical maps in functional neuroimaging using the false discovery rate. NeuroImage 15 (4), 870-878.

Gibson, E., 1998. Linguistic complexity: locality of syntactic dependencies. Cognition 68, 1-76.

Goel, V., Dolan, R.J., 2003. Explaining modulation of reasoning by belief. Cognition 87 (1), B11-B22.

Gordon, P.C., Grosz, B.J., Gilliom, L.A., 1993. Pronouns, names, and the centering of attention in discourse. Cogn. Sci. 17 (3), 311-347.

Graesser, A.C., Singer, M., Trabasso, T., 1994. Constructing inferences during narrative text comprehension. Psychol. Rev. 101 (3), 371-395.

Greene, S.B., McKoon, G., Ratcliff, R., 1992. Pronoun resolution and discourse models. J. Exp. Psychol.: Learn. Mem. Cogn. 18 (2), 266-283.

Greicius, M.D., Krasnow, B., Reiss, A.L., Menon, V., 2003. Functional connectivity in the resting brain: a network analysis of the default mode hypothesis. Proc. Natl. Acad. Sci. U. S. A. $100,253-258$.

Gusnard, D.A., Raichle, M.E., 2001. Searching for a baseline: functional imaging and the resting human brain. Nat. Rev., Neurosci. 2 (10), 685-694.

Hagoort, P., 2005. On broca, brain, and binding: a new framework. Trends Cogn. Sci. 9 (9), 416-423.

Hagoort, P., Brown, C.M., Osterhout, L., 1999. The neurocognition of syntactic processing. In: Brown, C.M., Hagoort, P. (Eds.), The Neurocognition of Language. Oxford University, pp. 273-316.

Hagoort, P., Hald, L., Bastiaansen, M., Petersson, K.M., 2004. Integration of word meaning and world knowledge in language comprehension. Science 304 (5669), 438-441.

Hammer, A., Goebel, R., Schwarzbach, J., Münte, T.F., Jansma, B.M., 2007. When sex meets syntactic gender on a neural basis during pronoun processing. Brain Res. 1146, 185-198.

Jung-Beeman, M., 2005. Bilateral brain processes for comprehending natural language. Trends Cogn. Sci. 9 (11), 712-718.

Kaan, E., Swaab, T.Y., 2002. The brain circuitry of syntactic comprehension. Trends Cogn. Sci. 6, 350-356.

Kiehl, K.A., Laurens, K.R., Liddle, P.F., 2002. Reading anomalous sentences: an event-related fMRI study of semantic processing. NeuroImage 17 (2), 842-850.

Kuperberg, G.R., Holcomb, P.J., Sitnikova, T., Greve, D., Dale, A.M., Caplan, D., 2003. Distinct patterns of neural modulation during the processing of conceptual and syntactic anomalies. J. Cogn. Neurosci. 15 (2), 272-293

Kuperberg, G.R., Lakshmanan, B.M., Caplan, D.N., Holcomb, P.J., 2006. Making sense of discourse: an fMRI study of causal inferenceing across sentences. NeuroImage 33, 343-361.

Kutas, M., Hillyard, S.A., 1980. Reading senseless sentences: brain potentials reflect semantic incongruity. Science 207 (4427), 203-205.

Maguire, E.A., Frith, C.D., Morris, R.G.M., 1999. The functional 
neuroanatomy of comprehension and memory: the importance of prior knowledge. Brain 122 (10), 1839-1850.

Marslen-Wilson, W., Tyler, L.K., 1980. The temporal structure of spoken language understanding. Cognition 8 (1), 1-71.

Mason, R.A., Just, M.A., Keller, T.A., Carpenter, P.A., 2003. Ambiguity in the brain: what brain imaging reveals about the processing of syntactically ambiguous sentences. J. Exp. Psychol.: Learn. Mem. Cogn. 29 (6), 1319-1338.

Myers, J.L., O’Brien, E.J., 1998. Accessing the discourse representation during reading. Disc. Process. 26, 131-157.

Newman, A.J., Pancheva, R., Ozawa, K., Neville, H.J., Ullman, M.T., 2001. An event-related fMRI study of syntactic and semantic violations. J. Psycholinguist. Res. 30 (3), 339-364.

Ni, W., Constable, R.T., Mencl, W.E., Pugh, K.R., Fulbright, R.K., Shaywitz, S.E., Shaywitz, B.A., Gore, J., 2000. An event-related neuroimaging study distinguishing form and content in sentence processing. J. Cogn. Neurosci. 12, 120-133.

Nieuwland, M.S., Van Berkum, J.J.A., 2006a. Individual differences and contextual bias in pronoun resolution: evidence from ERPs. Brain Res. $1118,155-167$

Nieuwland, M.S., Van Berkum, J.J.A., 2006b. When peanuts fall in love: N400 evidence for the power of discourse. J. Cogn. Neurosci. 18 (7), 1098-1111.

Nieuwland, M.S., Otten, M., Van Berkum, J.J.A., 2007. Who are you talking about? Tracking discourse-level referential processes with ERPs. J. Cogn. Neurosci. 19 (2), 1-9.

Novick, J.M., Trueswell, J.C., Thompson-Schill, S.L., 2005. Cognitive control and parsing: reexamining the role of Broca's area in sentence comprehension. Cogn. Affect. Behav. Neurosci. 5 (3), 263-281.

Osterhout, L., Mobley, L.A., 1995. Event-related brain potentials elicited by failure to agree. J. Mem. Lang. 34, 739-773.

Petersson, K.M., Nichols, T.E., Poline, J.B., Holmes, A.P., 1999. Statistical limitations in functional neuroimaging. II. Signal detection and statistical inference. Philos. Trans. R. Soc. Lond., B Biol. Sci. 354, 1261-1281.

Petersson, K.M., Sandblom, J., Elfgren, C., Ingvar, M., 2003. Instructionspecific brain activations during episodic encoding. A generalized level of processing effect. Neuroimage 20, 1795-1810.

Petersson, K.M., Gisselgård, J., Gretzer, M., Ingvar, M., 2006. Interaction between a verbal working memory network and the medial temporal lobe. NeuroImage 33, 1207-1217.

Ramnani, N., Owen, A.M., 2004. Anterior prefrontal cortex: insights into function from anatomy and neuroimaging. Nat. Rev., Neurosci. 5 (3), 184-194.

Ridderinkhof, K.R., Ullsperger, M., Crone, E.A., Nieuwenhuis, S., 2004. The role of the medial frontal cortex in cognitive control. Science 306 (5695), 443-447.

Robertson, D.A., Gernsbacher, M.A., Guidotti, S.J., Robertson, R.R.W., Irwin, W., Mock, B.J., Campana, M.E., 2000. Functional neuroanatomy of the cognitive process of mapping during discourse comprehension. Psychol. Sci. 11 (3), 255-260.

Rodd, J.M., Davis, M.H., Johnsrude, I.S., 2005. The neural mechanisms of speech comprehension: fMRI studies of semantic ambiguity. Cereb. Cortex 15 (8), 1261-1269.

Sanford, A.J., Garrod, S.C., 1989. What, when, and how? Questions of immediacy in anaphoric reference resolution. Lang. Cogn. Processes 4 (3-4), SI235-SI262.

Santi, A., Grodzinsky, Y., in press. Taxing working memory with syntax: bihemispheric modulations. Hum. Brain Mapp.

Shulman, G.L., Fiez, J.A., Corbetta, M., Buckner, R.L., Miezin, F.M., Raichle, M.E., Petersen, S.E., 1997. Common blood flow changes across visual tasks: II. decreases in cerebral cortex. J. Cogn. Neurosci. 9, $647-662$.

Singer, M., 1994. Discourse inference processes. In: Gernsbacher (Ed.), Handbook of Psycholinguistics. Academic Press, San Diego, pp. 479-515.

Smith, E.E., Jonides, J., 1999. Storage and executive processes in the frontal lobes. Science 283, 1657-1661.

Stowe, L.A., Haverkort, M., Zwarts, F., 2005. Rethinking the neurological basis of language. Lingua 115, 997-1042.

Tallon-Baudry, C., Bertrand, O., 1999. Oscillatory gamma activity in humans and its role in object representation. Trends Cogn. Sci. 3, $151-162$.

Tanenhaus, M.K., Trueswell, J.C., 1995. Sentence comprehension. In: Miller, Joanne L., Eimas, Peter D. (Eds.), Speech, Language, and Communication. Academic Press, San Diego, pp. 217-262.

Van Berkum, J.J.A., Brown, C.M., Hagoort, P., 1999. Early referential context effects in sentence processing: evidence from event-related brain potentials. J. Mem. Lang. 41, 147-182.

Van Berkum, J.J.A., Brown, C.M., Hagoort, P., Zwitserlood, P., 2003. Eventrelated brain potentials reflect discourse-referential ambiguity in spoken language comprehension. Psychophysics 40 (2), 235-248.

Van Berkum, J.J.A., Zwitserlood, P., Bastiaansen, M.C.M., Brown, C.M., Hagoort, P., 2004. So who's "he" anyway? Differential ERP and ERSP effects of referential success, ambiguity and failure during spoken language comprehension. Annual Meeting of the Cognitive Neuroscience Society, CNS-2004, San Francisco, April 18-20.

Van Berkum, J.J.A., Koornneef, A.W., Otten, M., Nieuwland, M.S., 2007. Establishing reference in language comprehension: an electrophysiological perspective. Brain Res. 1146, 158-171.

Van den Broek, P., 1994. Comprehension and memory of narrative texts: inferences and coherence. In: Gernsbacher, M.A. (Ed.), Handbook of Psycholinguistics. Academic Press, San Diego, pp. 539-588.

Volz, K.G., Schooler, L., Schubotz, R.I., Raab, M., Gigerenzer, G., von Cramon, D.Y., 2006a. Why you think Milan is larger than Modena: neural correlates of the recognition heuristic. J. Cogn. Neurosci. 18:11, 1-13.

Volz, K.G., Schubotz, R.I., von Cramon, D.Y., 2006b. Decision-making and the frontal lobes. Curr. Opin. Neurol. 19, 401-406.

Wagner, A.D., Shannon, B.J., Kahn, I., Buckner, R.L., 2005. Parietal lobe contributions to episodic memory retrieval. Trends Cogn. Sci. 9 (9), $445-453$.

Zwaan, R.A., Radvansky, G.A., 1998. Situation models in language comprehension and memory. Psychol. Bull. 123 (2), 162-185.

Zysset, S., Huber, O., Ferstl, E., von Cramon, D.Y., 2002. The anterior frontomedian cortex and evaluative judgment: an fMRI study. NeuroImage 15 (4), 983-991.

Zysset, S., Huber, O., Samson, A., Ferstl, E.C., von Cramon, D.Y., 2003. Functional specialization within the anterior medial prefrontal cortex: a functional magnetic resonance imaging study with human subjects. Neurosci. Lett. 335, 183-186. 